Sustainability Science • Sustainability Science: A guide for researchers

\title{
Terms \& Definitions in Sustainability Science
}

\author{
Alicia G. Harley, William C. Clark
}

Published on: Sep 10, 2020

DOI: $10.21428 /$ f8d $85 \mathrm{a} 02.6160 \mathrm{cec} 2$

License: Creative Commons Attribution 4.0 International License (CC-BY 4.0). 
Cite as: Harley, Alicia G., and William C. Clark. 2020. “Terms \& Definitions in Sustainability Science.” In Sustainability Science: A Guide for Researchers, edited by Alicia G. Harley and William C. Clark, 1st ed. Retrieved from https://www.sustainabilityscience.org/pub/blr4rdyc

Action situations: contexts of nature-society interactions in which particular actors, operating in particular institutional structures, make choices about using particular resources to achieve their particular goals

Actors: entities with agency - the ability to choose or decide; they include people, communities, firms, other organizations, and states, but also some nonhuman organisms and their assemblages (see also our definition for power)

Adaptation: response to potentially disruptive change that seeks to limit damage or seize opportunities for improvement to a development pathway within a regime (contrast with transformations, resilience)

Adaptation pathways: dynamical, and typically path-dependent, sequences of adaptations in which early adaptations influence the conditions that call for later adaptations

Anthropocene System: a term for what some call the earth system or world system that better captures the increasingly global and intimate intertwining of nature and society. (Wing and Members of the Anthropocene Working Group 2019).

Boundary work: process through which research communities organize their relations with new science, other sources of knowledge, and the worlds of action and policy-making

Capacity: the intention and the ability to accomplish a task or achieve an outcome

Capital assets: resource stocks - both natural and anthropogenic-on which society draws for its wellbeing (see Table 2)

Complex adaptive systems (CAS): relationships among diverse elements that give rise to novelty and dynamics that feed back on those elements and relationships, resulting in a continually evolving system

Co-production: knowledge and society continually shaping each other in a dynamic, path-dependent process

Disruptions: shocks, surprises, innovation, and the unfolding unknown

Elements: variables or components of structure; may be coupled via functional relationships or processes 
Fit: emphasizes the importance of matching governance arrangements to the characteristics of the action situation being governed

Frameworks: the most general form of conceptualization in science; provide checklists or building blocks for consideration in constructing theories or models (Ostrom 2011).

Governance: the arrangements by which any collectivity, from the local to the global, seeks to manage its common affairs (uggㄹㄹ 2014).

Heterogeneity: characteristics of actors and other elements that are distinctive and cannot be understood in terms of averages (also referred to as individuality or diversity)

Hysteresis: the tendency of a system change to be irreversible even when forces that caused the change are reversed

Imaginaries: collectively held visions of good or attainable futures that serve to envision the possible and motivate action toward new development pathways

Incumbency: relationships among actors and institutions through which power differentials shape, stabilize, and reinforce existing regimes and their associated development pathways

(In)equality: a positive or descriptive concept referring to the distribution of assets or freedoms among actors

(In)equity: a normative concept referring to the qualities of justness, fairness, and impartiality

Informed agitation: the arousing of public concern about an issue, through the means of knowledge sharing, research, and deliberation, for the purpose of bringing about action (Sen 2013).

Innovation: the interplay of actors, institutions, goals, and resources through which new artifacts and practices are invented, selected, adapted, adopted, and brought into widespread use

Institutions: the rules, norms, rights, culture, and widely shared beliefs that shape the behavior of social actors in their relationships with one another and with nature

Logics of appropriateness: the idea that action is often driven by norms of behavior rather than by rules and regulations alone; asks "what does a person such as I do in a situation such as this?" (March and Olsen 2011).

Multi-level perspective (MLP): a hierarchical framework for analyzing innovation in sociotechnical systems 
Pathways of development: temporal changes in patterns of observed or predicted covariation in nature and society

Polycentric: systems with multiple sources of partial authority and semiautonomous decision-making that interact to create multi-level governance arrangements

Power: the ability of actors to deploy their agency in ways that affect the beliefs or actions of other actors

Productive base: the total set of resource stocks or capital assets on which society draws for its wellbeing

Public Trust Doctrine (PTD): holds that governments have a legal duty to hold certain natural resources in trust on behalf of present and future citizens

Reflexive governance: governance arrangements that promote the ability to question one's own core commitments

Regimes: sets of dominant relationships (both natural and social) that give rise to characteristic dynamics and development pathways

Resilience: a system's ability to utilize the "breathing room" provided by its robustness to disturbance to fundamentally change how it uses resources under the new conditions (see also adaptation, transformations)

Risk: the prospect of loss or gain under uncertainty of something thought to be of value, often incorporating estimates on the likelihood of a change and consequences if the change occurs

Safe spaces: institutional arrangements that encourage experimentation and the timely acknowledgment of error

Threshold: condition at which small changes can have big effects, leading to qualitatively different pathways of development; closely related to tipping point and catastrophic bifurcation

Transformations: shifts from one regime and its associated development pathways to another; also called transitions (contrast with adaptation)

Vulnerability: the likelihood that a particular subpopulation will lack or lose access to the resources they need to secure their well-being in the face of disruptions

Well-being: an integrating concept of the good life, the constituents of which will vary among people and across time 


\section{Citations}

1. Wing, Scott, and Members of the Anthropocene Working Group. 2019. "Letters: 'The Anthropocene Epoch Is Not Hubris." The Atlantic, October 11, 2019. https://www.theatlantic.com/letters/archive/2019/10/readers-defend-the-anthropoceneepoch/597571/.

2. Ostrom, Elinor. 2011. "Background on the Institutional Analysis and Development Framework." Policy Studies Journal 39 (1): 7-27. https://doi.org/10.1111/j.1541-0072.2010.00394.x.

3. Ruggie, John Gerard. 2014. “Global Governance and 'New Governance Theory': Lessons from Business and Human Rights." Global Governance 20 (1): 5-17. $\Perp$

4. Sen, Amartya. 2013. "The Ends and Means of Sustainability." Journal of Human Development and Capabilities 14 (1): 6-20. https://doi.org/10.1080/19452829.2012.747492.

5. March, James G., and Johan P. Olsen. 2011. “The Logic of Appropriateness." In The Oxford Handbook of Political Science, edited by R. Goodin, 478-497. Oxford, UK: Oxford Univ. Press. $ヒ$ 